Article

\title{
Anti-Inflammatory, Antimicrobial, and Vasoconstriction Activities of an Anti-Hemorrhoidal Mixture of Alchemilla vulgaris, Conyza bonariensis, and Nigella sativa: In Vitro and Clinical Evaluations
}

\author{
Omar Said ${ }^{1, *}$, Iyad Khamaysi ${ }^{2}$, Abdalsalam Kmail ${ }^{3}$,, Omar Sadiq $^{3}$, Besan Saied ${ }^{1}$, Stephen Fulder ${ }^{1}$, \\ Basheer Abofarekh ${ }^{4}$, Mahmud Masalha ${ }^{4}$, Riyad Amin ${ }^{1}$ and Bashar Saad ${ }^{3,4, *}$ (D) \\ 1 Independent Researcher, Beleaf Pharma, P.O. Box 2205, Kfar Kana 16930, Israel; besan.saied@gmail.com (B.S.); \\ fulder@zahav.net.il (S.F.); riyad@gmail.com (R.A.) \\ 2 Faculty of Medicine, Technion-ITT, Rambam Medical Center, P.O. Box 155, Haifa 2611001, Israel; \\ k_iyad@rambam.health.gov.il \\ 3 Faculty of Medicine, Arab American University Jenin, P.O. Box 240, Jenin P201, Palestine; \\ abdalsalam.kmail@aaup.edu (A.K.); omar.sadiq@aaup.edu (O.S.) \\ 4 Qasemi Research Center, Al-Qasemi Academy, P.O. Box 124, Baqa al-Gharbiyye 30100, Israel; \\ af_basheer@qsm.ac.il (B.A.); MahmudMasalha@gmail.com (M.M.) \\ * Correspondence: omar@beleafherbal.com (O.S.); bashar.saad@aaup.edu or bashar@qsm.ac.il (B.S.)
}

Citation: Said, O.; Khamaysi, I.; Kmail, A.; Sadiq, O.; Saied, B.; Fulder, S.; Abofarekh, B.; Masalha, M.; Amin, R.; Saad, B. Anti-Inflammatory, Antimicrobial, and Vasoconstriction Activities of an Anti-Hemorrhoidal Mixture of Alchemilla vulgaris, Conyza bonariensis, and Nigella sativa: In Vitro and Clinical Evaluations. Immuno 2022, 2, 132-150. https://doi.org/ 10.3390/immuno2010010

Academic Editor: Young-Su Yi

Received: 23 December 2021

Accepted: 20 January 2022

Published: 26 January 2022

Publisher's Note: MDPI stays neutral with regard to jurisdictional claims in published maps and institutional affiliations.

Copyright: (C) 2022 by the authors. Licensee MDPI, Basel, Switzerland. This article is an open access article distributed under the terms and conditions of the Creative Commons Attribution (CC BY) license (https:// creativecommons.org/licenses/by/ $4.0 /)$.

\begin{abstract}
Nigella sativa, Conyza bonariensis, and Alchemilla vulgaris are highly recommended in GrecoArab traditional medicine as anti-hemorrhoid medicinal plants. The efficacy and safety of a topical cream (HPC) consisting of water-ethanol extracts of these three plants were evaluated here in vitro and in a randomized, double-blind, placebo-controlled study (RDBPC). HPC showed no significant cytotoxic effects in fibroblast cell line 3T3 (LDH-release and MTT assay); it inhibited the nitric oxide production by cultured monocyte cell line THP-1 in a dose-dependent manner (reaching the control levels of untreated cells at a concentration of $100 \mu \mathrm{g} / \mathrm{mL}$ ). HPC showed a dose-dependent antibacterial activity against Escherichia coli (60\% inhibition compared to Ampicillin at $5 \mathrm{mg} / \mathrm{disc}$ ) and a significant vasoconstriction effect on intestinal vein rings ( $40 \%$ increase compared to phenylephrine). In a RDBPC with 77 hemorrhoidal disease (patients ages 19-61 years with a median grade of hemorrhoids of 2.0), we determined the anti-hemorrhoid efficacy and safety of HPC. The patients were randomly assigned to the HPC group (54 patients) or the placebo group (23 patients). They were asked to apply 2-3 mL of HPC or placebo twice daily for 6 days. The degree of hemorrhoidal disease severity, hemorrhage severity, pain, and itching served as an evaluation of the HPC efficacy. Compared to the placebo group, the obtained results showed that 6 days of treatment with HPC reduced the indexes of hemorrhage severity, severity of pain, and severity of itching to $0-1,1$, and 1 after 6 days, respectively. In conclusion, patients treated with HPC had a significant clinical improvement in all disease severity parameters compared to placebo. In vitro evaluations proved HPC to have significant antimicrobial, anti-inflammatory, and vasoconstriction effects. Therefore, HPC represents an interesting alternative treatment for hemorrhoidal disease.
\end{abstract}

Keywords: hemorrhoidal disease; anti-inflammatory; vasoconstriction; Nigella sativa; Conyza bonariensis; Alchemilla vulgaris

\section{Introduction}

Hemorrhoids are characterized by enlargement, bleeding, and protrusion of clusters of veins in the anus located under the membrane that lines the lowest part of the rectum and anus. It is estimated that hemorrhoids affect $5 \%$ of the general population, with $50 \%$ of people over the age of 50 having experienced symptoms of hemorrhoidal disease (HD). Pathologic symptoms of HD include fissures, fistulae, abscesses, or irritation and 
itching [1-3]. Hemorrhoids can be either internal or external. The former occur inside the rectum and are usually not painful because this area lacks sensitive nerve endings. External hemorrhoids occur outside of the anal verge and are usually painful, accompanied by pruritus, itching, swelling, and burning sensations [1,2].

Possible HD causes include genetics, constipation or diarrhea, complications from chronic constipation, pregnancy, and obesity. These conditions lead to pressure elevation within the submucosal arteriovenous plexus and eventually result in swelling of the clusters of veins, laxity of the supporting connective tissue, and protrusion into and through the anal canal [3,4].

The natural history of most cases of hemorrhoid disease is self-limited. For symptomatic HD that presents to the clinic or emergency room, treatments range from nonoperative medical interventions and office-based procedures to surgery. One general guiding principle is that the least invasive approaches should be considered first, except in cases of acute thrombosis. Specific choices of treatments depend on patients' ages, severity of symptoms, and comorbidities [3-6].

Lifestyle and dietary modification are the mainstays of conservative medical treatment of HD. Specifically, lifestyle modifications should include increasing oral fluid intake, reducing fat consumption, avoiding straining, and regular exercise. Diet recommendations should include increasing fiber intake, which decreases the shearing action of passing hard stool. In a meta-analysis of seven randomized trials comparing fiber to non-fiber controls, fiber supplementation $(7-20 \mathrm{~g} / \mathrm{d})$ reduced the risk of persisting symptoms and bleeding by $50 \%$. However, fiber intake did not improve symptoms of prolapse, pain, and itching.

For internal hemorrhoids, rubber band ligation, sclerotherapy, and infrared coagulation are the most common procedures but there is no consensus on optimal treatment. Overall, the goals of each procedure are to decrease vascularity, reduce redundant tissue, and increase hemorrhoidal rectal wall fixation to minimize prolapse.

Continued symptoms despite conservative or minimally invasive measures usually require surgical intervention. In addition, surgery is the initial treatment of choice in patients with symptomatic grade-IV hemorrhoids or those who have strangulated internal hemorrhoids. It may also be required for symptomatic grade-III hemorrhoids and in patients who present with thrombosed hemorrhoids.

The vast number of treatment options means that there is no gold standard. There is no single best treatment for hemorrhoids and various options are available depending upon symptoms and grading. Any treatment has to be safe, especially while treating non-life threatening conditions such as hemorrhoids [3,4].

Due to various side effects, drug interactions, and the high costs of synthetic drugs, interest in herbal medicines is increasing day by day. Among the population, the variety of plants used against hemorrhoids is quite high. For example, 241 medicinal plants are used to treat hemorrhoids in various regions of Turkey [5-11]. Nigella sativa (NS), Conyza bonariensis $(C B)$, and Alchemilla vulgaris $(A V)$ are highly recommended for treating HD in the traditional Greco-Arab herbal medicine. They are reported to improve the symptoms of hemorrhoids such as pain, bleeding, itching, rectal prolapse, number of hemorrhoidal cushions, and recurrence of/increase in the rate of wound healing. Their mechanisms of action include anti-inflammatory, anti-nociceptive, venotonic, and venoprotective activities [1-5].

The seeds of NS have been used in different traditional medicines around the world for centuries to treat various human diseases. So far, numerous studies have demonstrated that the seeds of NS and its main active constituent (thymoquinone, a strong anti-oxidant and anti-inflammatory agent) to be therapeutically effective against various chronic diseases, such as neurological and mental illness, cardiovascular disorders, cancer, diabetes, inflammatory conditions, and infertility as well as various infectious diseases caused by bacterial, fungal, parasitic, and viral infections [6,12].

$C B$ was found to exert antioxidant, anti-inflammatory, antinociceptive, and antipyretic effects. In addition, the growth-inhibitory activity of this plant against a series of selected microbial strains has also been reported. This plant is widely used in various traditional 
medicines in the treatment of rheumatism, gout, cystitis, nephritis, dysmenorrhea, tooth pain, and headache; it was also reported to have antiulcerogenic and anticoagulant activity, as well as antioxidant effects [6,12].

Alchemilla plants (lady's mantle) are used in traditional medicine for different indications, including minimizing the symptoms of sore throat, stopping bleeding, acting against gastrointestinal diseases and inflammatory processes, as well as for promoting wound healing due to its strong antimicrobial and anti-inflammatory effects [13-18].

The concept of mixing plants to make a more effective poison or medicine is an ancient and very popular tradition. In our research group, we have conducted in vitro, in vivo, and clinical trials on anti-diabetes, anti-overweight, anti-acne, and anti-hyperlipidemia medicinal plant mixtures [6,7,15,19-21]. Based on knowledge from traditional Greco-Arab herbal medicine, and the results obtained in our survey [6,14] and other ethnopharmacological potential studies, we selected the most promising three medicinal plants, namely $N S, C B$, and $A V$, for preparing a topical HPC cream consisting of water-ethanol extracts of these three plants. These plants have been used extensively in traditional Greco-Arab medicine in the treatment of hemorrhoids and other chronic diseases [5-11]. The present in vitro animal study and RDBPC aim to determine the safety and efficacy of HPC.

\section{Materials and Methods}

\subsection{Preparation of Plant Extracts}

$N S, C B$, and $A V$ were collected from the Galilee region during the spring and summer months. The botanical identities of the collected plant materials were confirmed by Prof. Hasan Azaizeh (Department of Environmental Sciences, Tel-Hai Academic College, Israel). The voucher specimens of NS, CB, and $A V$ were NS 2014/03/006, CB 2014/04/008, and $A V$ 2014/05/012. The water-ethanol extracts of the plant materials were produced as described [15]. In brief, $100 \mathrm{~g}$ of NS (seeds), $C B$ (branches and flowering parts), or $A V$ (leaves) were added to one liter of $50 \%$ ethanol in distilled water and boiled for $10 \mathrm{~min}$. The extracts were filtered through filter paper and frozen at $-70{ }^{\circ} \mathrm{C}$ until use. All the experimental work on plant material described in this study complies with the relevant institutional, national, and international guidelines and legislation.

\subsection{Preparation of HPC Cream}

The herbal "HPC" cream was prepared from specific quantities of extracts of $N S, C B$, $A V$, glycerol, and basic creams, as described in Table 1. All experimental protocols of this study were approved by the ethics committee of the Rambam Hospital in Haifa, and were carried out in accordance with relevant guidelines and regulations as well as with ARRIVE guidelines.

Table 1. Plant extracts used in the preparation of the anti-hemorrhoidal polyherbal cream (HPC).

\begin{tabular}{cccc}
\hline Botanical Name & $\begin{array}{c}\text { English Common Name } \\
\text { (Part Used) }\end{array}$ & Weight (g/50 $\mathbf{~ L ) ~}$ & \% w/w \\
\hline Nigella sativa & Black Cumin (seeds) & 0.5 & 1.0 \\
\hline Alchemilla vulgaris L. & lady's mantle (leaves) & 0.3 & 0.6 \\
\hline Conyza canadensis & $\begin{array}{c}\text { Flax-leaf Fleabane (branches } \\
\text { and flowering parts) }\end{array}$ & 0.3 & 0.6 \\
\hline & Glycerin & 2 & 4 \\
\hline Basic cream & 46.9 & 93.8 \\
\hline Total (50 gr/U) & 50 & 100 \\
\hline
\end{tabular}

Pharmaceutical Manufacturing Process

Emulsifiers were melted with sunflower seed oil at a temperature of $70 \pm 5^{\circ} \mathrm{C}$. Separately, the aqueous phase (water, HPC, preservatives) was heated to the same temperature 
of $70 \pm 5{ }^{\circ} \mathrm{C}$. Then, the oily phase was added to the aqueous phase. The mixture was emulsified using homogenizer at $5000 \mathrm{rpm}$ for 20-30 min. The resulted homogenous and white colored cream. In addition, the consistency, appearance, and stability of the cream were examined and approved.

\subsection{Cell Culture}

The fibroblast cell line 3T3 (CRL-1658) and the human monocyte cell line THP-1 (202TIB) were obtained from the ATCC (American Type Culture Collection, Manassas, VA, USA) and maintained under standard cell culture conditions in high-glucose $(4.5 \mathrm{~g} / \mathrm{L})$ Dulbecco's modified Eagle's medium (DMEM) and Roswell Park Memorial Institute Medium (RPMI 1640), respectively. Both media were supplemented with 10\% fetal bovine serum (FBS), $1 \%$ nonessential amino acids, $1 \%$ glutamine, $100 \mathrm{U} / \mathrm{mL}$ penicillin, and $10 \mu \mathrm{g} / \mathrm{mL}$ streptomycin. THP- 1 cells were grown at a density of $2 \times 10^{5}$ cells $/ \mathrm{mL}$. Their differentiation into macrophages was induced by adding Phorbol-12-Myristate-13 Acetate (PMA, purchased from Sigma-Aldrich, MA, USA) $(100 \mathrm{ng} / \mathrm{mL})$ and vitamin D3 $(0.1 \mu \mathrm{M})$ (purchased from Sigma-Aldrich, MA, USA) to the culture medium for $24 \mathrm{~h}$. Cells were then treated with various concentrations of the $\mathrm{HPC}(0,180$, and $360 \mu \mathrm{g}$ of $\mathrm{HPC} / \mathrm{mL})$.

\subsection{Cell Viability}

Lactate dehydrogenase (LDH) leakage assay was carried out to evaluate non-toxic concentrations of the three medicinal plants. Cell viability of cultured 3T3 cells was evaluated using the CytoTox 96 (cytotoxicity assay kit, Promega, Israel), according to the manufacturer's instructions. Briefly, 96-well plates were used to culture of $2 \times 10^{3}$ cells/well of fibroblast cell line $3 \mathrm{~T} 3$ for $24 \mathrm{~h}$ at $37^{\circ} \mathrm{C}$. Culture media was then replaced by media containing without HPC (control) or with 180, $360 \mu \mathrm{g} \mathrm{HPC/mL} \mathrm{for} 24 \mathrm{~h}$. DMEM additionally supplemented with $0.01 \mathrm{vol} \%$ of a cytotoxic surfactant (Triton X-100, Sigma-Aldrich, USA) was used as a positive control. The concentrations of LDH in cell lysates or centrifuged culture media were evaluated as described [15].

For the MTT assay: 20,000 cells $/ 100 \mu \mathrm{L}$ media from the $3 \mathrm{~T} 3$ cells cell line were seeded in 96-microtiter plates. Twenty-four hours later, cells were treated with culture media was then replaced by media containing without HPC (control) or with 180 or $360 \mu \mathrm{g} \mathrm{HPC/mL}$ for $24 \mathrm{~h}$. The MTT assay was then performed.

\subsection{Nitrite Determination}

Griess reagent assay was applied to measure the inhibitory effects of NO production on THP-derived macrophages, as described in [22,23].

\subsection{Antimicrobial Activity with Standardized Disk Diffusion Assay}

This standardized technique was carried out as described in [21]. Briefly, Escherichia coli (E. coli) strains (ATCC-25922) were cultured in Reinforced Clostridium Medium (RCM) for $48 \mathrm{~h}$ and adjusted to yield approximately $1.0 \times 10^{6} \mathrm{CFU} / \mathrm{mL}$. A $1.0 \times 10^{8} \mathrm{CFU}$ inoculum was spread on blood agar (with sheep blood 5 to $7 \%$, obtained from Promega) (BASB) medium plates. Whatman filter discs of $6 \mathrm{~mm}$ diameter were placed in autoclaved glass Petri dishes. The bacterial suspension $\left(10^{8} \mathrm{CFU} / \mathrm{mL}\right)$ was swabbed on the surface of $5-7 \%$ BASB-medium plates. The HPC discs (1, 2 and $5 \mathrm{mg} /$ disc) were then distributed evenly on the surface of the seeded agar plate. The Ampicillin reference antibiotics discs $(10 \mathrm{mg} / \mathrm{disc})$ were placed onto the agar plate beside the extract discs. The BASB-plates were incubated upside down in Gaspak jars at $37^{\circ} \mathrm{C}$ for $48 \mathrm{~h}$. The inhibition zone around each disc was then measured using a transparent ruler. Three replicate plates were used for each test.

\subsection{Vasoconstriction Effect of HPC on Intestinal Vein Rings}

The study was conducted in the faculty of medicine, Technion, Haifa, Israel, under the supervision of Dr Omar Said. Blood vessels were harvested from Sprague-Dawley male rats as described $[24,25]$. Intestinal vein rings were obtained and each ring was suspended 
by a fine steel wire and connected to an isometric tension transducer (Myograph F60). The transducer was connected to a Narco Trace 40 polygraph (Narco-Bio-Systems Inc., TX, USA). The rings were maintained in $15 \mathrm{~mL}$ Krebs-Henseleit solution at $37^{\circ} \mathrm{C}$ bubbled with $95 \% \mathrm{O}_{2}$ and $5 \% \mathrm{CO}_{2}$. A tension of $500 \mathrm{mg}$ was maintained during an equilibrium period of $60 \mathrm{~min}$ during which the bathing medium was changed every $20 \mathrm{~min}$. The rings were exposed to cumulative concentrations of phenylephrine with the presence and absence of $10 \mathrm{mg} / \mathrm{mL}$ of HPC.

\subsection{Open-Label, Uncontrolled, Safety/Efficacy Study to Evaluate the Safety and Efficacy of HPC in the Treatment of Hemorrhoids}

The protocol of the study was reviewed and approved by the ethics committee of the Rambam Hospital, Israel (ethics approval number/date: 0330-13-RMB/23072013). The study was conducted in accordance with the relevant guidelines and regulations of the ethics committee of the Rambam Hospital, Israel. Dr Iyad Khamaysi (Gastroenterologist, Rambam Hospital, Haifa, Israel) carried out this open-label clinical study in 2014 on 37 patients (17 females and 20 males, ages 19-59) in his clinic in the Galilee region. All the patients were evaluated clinically and endoscopically and were asked to apply HPC twice daily for one week. Five of the 37 patients who also suffered from mild anal fissure were excluded. Significant improvement in the clinical parameters [26] grade of hemorrhoids (1-4), hemorrhage (0-3), pain (0-10), and itching (0-3) served for evaluation of the HPC efficacy. The hemorrhoid severity degree grade for all the 37 patients was as follows: 10 patients with degree grade 1,18 with degree grade 2 , and 9 with degree grade 3 . The trial criteria were the same as described for RDBPC in Section 2.9.

\subsection{RDBPC to Determine the Anti-Hemorrhoidal Efficacy and Safety of HPC}

The protocol of the study was reviewed and approved by the ethics committee of the Rambam Hospital, Israel (ethics approval number/date: 0330-13-RMB/23072013). The study was conducted in accordance with the relevant guidelines and regulations of the ethics committee of the Rambam Hospital, Israel. This RDBPC to determine the antihemorrhoidal efficacy and safety of HPC was carried out in 2015 by Dr Iyad Khamaysi (Department of Gastroenterology, Rambam Hospital, Haifa, Israel) on 77 hemorrhoids patients with median grade of hemorrhoids of 2.0. The patients were randomly divided into test group ( $n=54$, aged 19-61 years, 27 females and 27 males) and placebo group ( $n=23$, ages $19-56$ years, 11 females and 12 males with a median grade of hemorrhoids 2.0) (Figure 1). The patients were asked to apply $2-3 \mathrm{~mL}$ of HPC twice daily for 6 days. Each patient came for 5 visits and follow-up: at baseline, at days 2, 4, and 6, and at the observation endpoint after one month. Changes in the Hemorrhoids Disease Severity (HDS) (0-3), Hemorrhage Severity (HS) (0-3), pain (0-10), and itching (0-3) measures served for evaluation of the HPC cream efficacy. The baseline hemorrhoid severity degree of the test group $n=54$ was diagnosed as follows: 9 patients with degree 1, 19 with degree 2, 26 with degree 3 . While the placebo group $n=23$ was diagnosed as follows: 6 patients with degree 1,7 with degree 2,10 with degree 3 .

Eligibility: To be eligible for this study, qualified participants needed to be (1) either male or female and aged 18 years and up, (2) diagnosed as suffering from hemorrhoids and willing to give informed consent, and (3) willing to refrain from using any other hemorrhoids medications while participating in the trial.

Inclusion Criteria: (1) Providing a written informed consent and ability to fulfill the requirements of the willingness to participate in the study and agreement to all study procedures. (2) Diagnosed with symptomatic internal hemorrhoids, diagnosed by both clinical and endoscopic assessment (grades I-III). (3) Refraining from the use of any other hemorrhoid medications. 


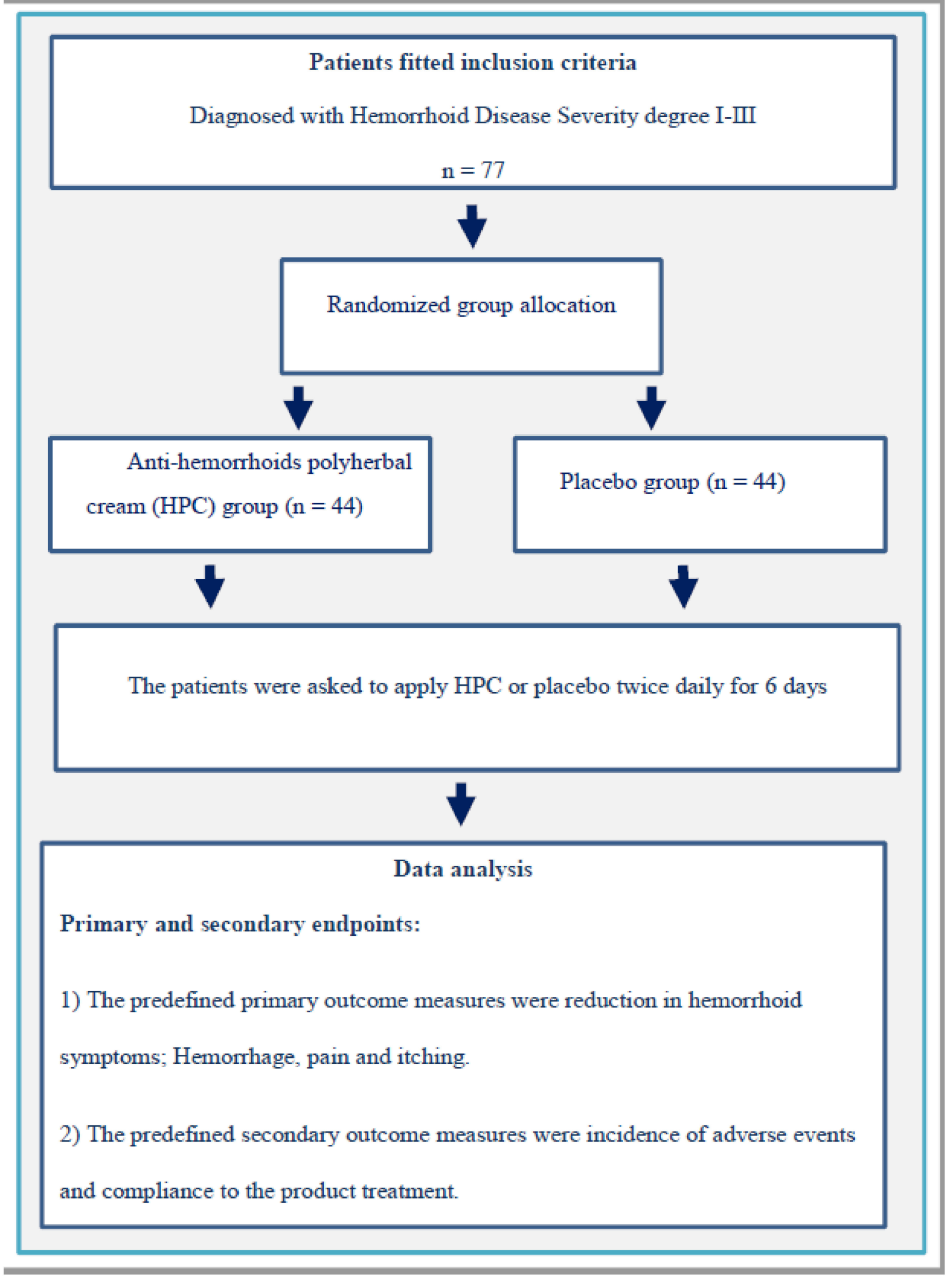

Figure 1. A flow chart of the randomized, double-blind, placebo-controlled clinical trial procedure.

Exclusion Criteria: (1) History of inflammatory bowel disease. (2) History of irritable bowel syndrome with constipation or diarrhea. (3) Previous surgical or instrumental 
treatment of internal hemorrhoids. (4) Topical anesthetics within 14 days prior to day 1. (5) Any investigational agents within 28 days before day 1. (6) Diagnosis with hemorrhoid Disease Severity degree IV. (7) Use of anal, intra-anal, or intra-rectal steroids within 28 days before day 1.

Primary and secondary endpoints: (1) The predefined primary outcome measures were a reduction in hemorrhoid symptoms, namely hemorrhage, pain, and itching. (2) The predefined secondary outcome measures were the incidence of adverse events and compliance with the treatment.

\subsection{Statistical Analysis}

Error limits cited and error bars plotted represent simple standard deviations of the mean. Usually, numerical results are given only to an accuracy sufficient to specify the least significant digit. When comparing different samples, results were considered to be statistically different when $p<0.05$ (Student's $t$ test for unpaired samples).

\section{Results and Discussion}

There is a plethora of medicinal plants and their therapeutic uses are mentioned in traditional Greco-Arab herbal medicine scripts written by famous medieval scholars such as Avicenna, Rhazes, and Ibn al-Bitar [6]. Many of these medicinal herbs are currently used in the treatment and prevention of all types of human diseases within the Mediterranean regions [27]. For example, 241 herbs are used in the treatment of various types of HD in various regions of Turkey [5]. Although most of these medicinal plants have a long history of traditional use, they lack sufficient evidence-based scientific data that are needed for approval as a new drug at the current time. Most of the published data dealing with anti-hemorrhoidal properties are based on in vitro or animal studies and, thus, there are many gaps in their efficacy and safety profiles. Therefore, it is essential to complete preclinical safety and efficacy evaluations of these medicinal plants and then go through clinical trials to prove their efficacy. There is a plethora of studies that suggest that the use of herbal mixtures is more effective in the treatment of HD compared to single plant treatment $[2,5,6]$. This is most probably due to possible synergistic effects, though these remain to be elucidated.

$N S, C B$, and $A V$ are highly recommended for treating HD in the traditional GrecoArab herbal medicine [6,27]. However, few studies, if any, have evaluated their synergistic anti-hemorrhoidal effects. The results of the present study demonstrated that the mixture of the three plants used as a topical cream was effective for the management of HD. The improvement was probably due to the antimicrobial, anti-inflammatory, antioxidant, and healing properties of the mixture.

\subsection{Cytotoxicity Measurements}

Cytotoxic effects of HPC were evaluated in the first phase of this study in cells from the mouse fibroblast cell line 3T3. Figure 2 depicts the results of LDH release (A) and MTT assay (B) at 24, 48, and $72 \mathrm{~h}$ of incubation time with 0,180 , and $360 \mu \mathrm{g}$ of $\mathrm{HPC} / \mathrm{mL}$. Compared to untreated control cells, no significant change in LDH-release was found whether as a function of increasing the HPC concentration or as a function of increasing the incubation period. Treatment with Triton X-100 as positive control increased the LDH release by $430 \pm 27 \%$ compared to untreated cells (data not shown).

These results support the long history of safe use of the three herbs and published data regarding the biosafety of the individual plants. The LD50 values for $N S, C B$, and $A V$ are $19.8,17.8$ and $17.3 \mathrm{~g} / \mathrm{Kg}$ weight, respectively $[15,26]$.

\subsection{Antibacterial Activities}

Plants can be effective in the treatment of hemorrhoids through anti-bacterial, antiinflammatory, anti-oxidant, and wound-healing activities [1-5]. The plants with essential oils, flavonoids, alkaloids, and phenolic compounds are well known for their antibacterial 
effects including inhibitory action against acne-inducing bacteria [5]. The antimicrobial activity of HPC against $E$. coli was evaluated here using the disc diffusion method. Inhibition zone diameters were measured to evaluate the antimicrobial activities of HPC against $E$. coli, compared with the reference antibiotic (Ampicillin). HPC showed a dosedependent antibacterial activity against $E$. coli, reaching $60 \%$ of the inhibition observed with the Ampicillin at $5 \mathrm{mg} /$ disc (Figure 3). There are many reports on the anti-bacterial action of the three plants of HPC $[2,5,11-13,17,28-30]$. However, the observed relatively high antibacterial (compared to Ampicillin) effects in this study could be due to the synergistic effects of all three plant extracts.

A

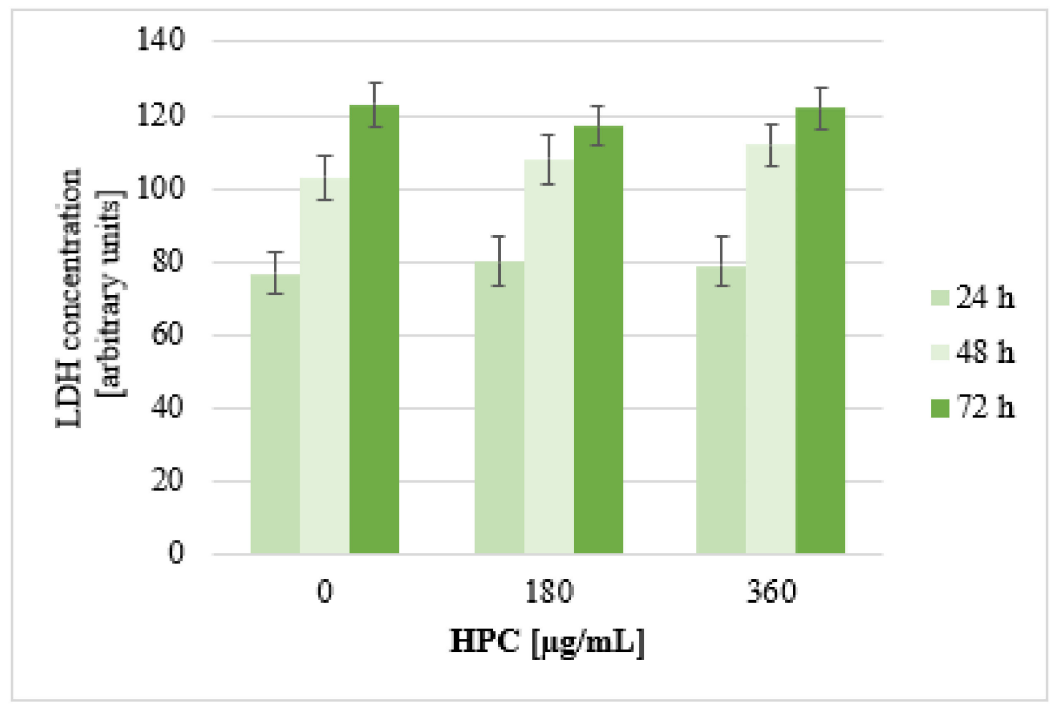

B

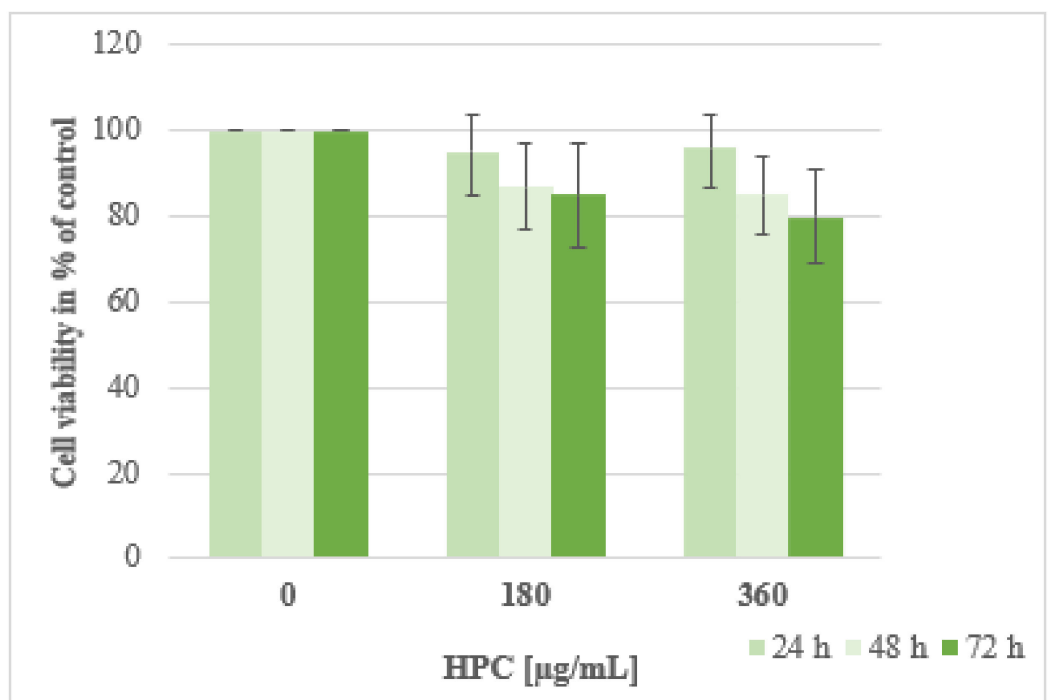

Figure 2. LDH-release (A) and MTT assay (B) using cultured cells from fibroblast cell line 3T3. Cells were treated with anti-hemorrhoidal polyherbal cream $(\mathrm{HPC})(0,180$, and $360 \mu \mathrm{g} / \mathrm{mL})$ for $24 \mathrm{~h}, 48 \mathrm{~h}$, and $72 \mathrm{~h}$. Data shown represent the mean \pm SEM from three independent experiments carried out in triplicates. 


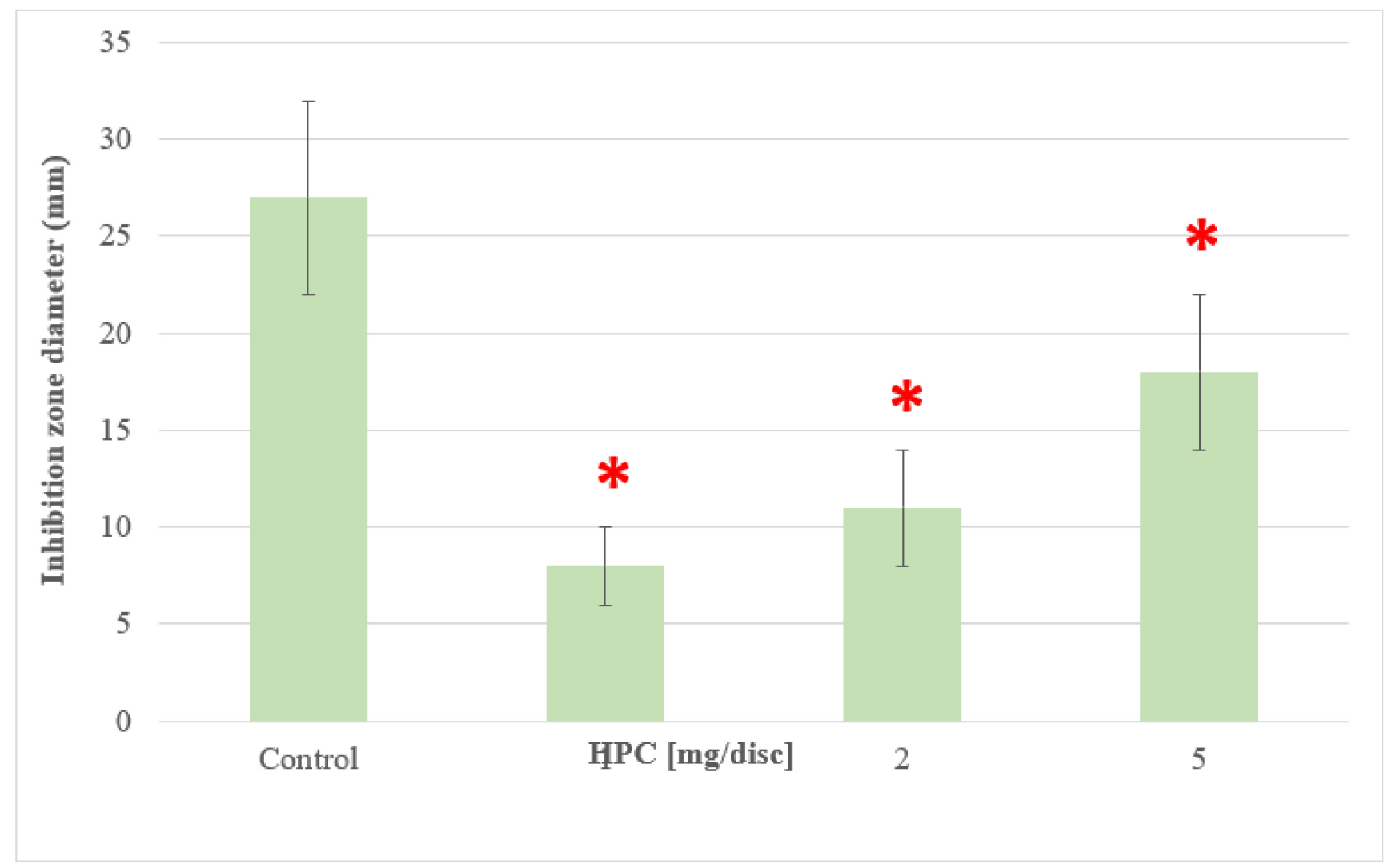

Figure 3. Antibacterial effects of the HPC. The inhibition zones' diameters were measured to evaluate the antimicrobial activities of the anti-hemorrhoidal polyherbal cream (HPC) against E. coli, compared with $5 \mathrm{mg}$ Ampicillin/disc (control). Values represent means \pm SD of three independent experiments carried out in triplicates. ${ }^{*} p<0.01$ - significant as compared with control.

\subsection{Effects of HPC on Nitric Oxide Production (NO)}

It is well known that HD is characterized by severe vasodilatation at the anal region, which leads to inflammation of the surrounding tissues and to further secondary complications such as extravasation of fluid into interstitial spaces mainly due to increased vascular permeability and migration of inflammatory cells [1]. These newly migrated inflammatory cells (monocytes, lymphocytes, neutrophils, and eosinophils) begin to release pro-inflammatory cytokines (TNF- $\alpha$ and IL-6) and free radicals (NO). These factors activate anus-resident cells (fibroblasts, endothelial cells, macrophages, and mast cells), leading to systemic inflammatory responses (fever and cachexia) [15]. Evidence for the role of pro-inflammatory cytokines and NO in the pathogenesis of hemorrhoids suggests that anti-inflammatory agents may be of therapeutic use in the treatment of HD. A large number of medicinal plants and their derived phytochemicals were reported to exhibit significant anti-inflammatory effects in in vitro as well as animal models. The LPS-activated human monocytic cell line THP-1 was used here to measure the anti-inflammatory effects of HPC. LPS-activated THP- 1 cells are known to secret various pro-inflammatory cytokines, such as TNF- $\alpha$, IL-1 $\beta$, or IL- 6 , as well as NO [15,31-33]. The secretion levels of NO by cultured THP-1 was measured in the culture supernatants using Gries reagent. Figure 4 shows the dose-dependent inhibition of the LPS mediated production of NO. HPC inhibited the NO production by cultured THP- 1 cells in a dose-dependent manner, reaching the control levels of untreated cells at a concentration of $100 \mu \mathrm{g} / \mathrm{mL}$. There are many reports on the antiinflammatory action of three plants of HPC, in particular NS. Different immunomodulatory and immunotherapeutic properties of NS have been published. These publications provide clear evidence that both crude extracts and active compounds, in particular thymoquinone, exhibit significant anti-oxidant effects by enhancing the oxidant scavenger system, which 
consequently leads to antitoxic effects. The NS oil and thymoquinone have exhibited potent anti-inflammatory effects on several inflammation-based models including experimental encephalomyelitis, colitis, peritonitis, edema, and arthritis through suppression of the pro-inflammatory mediators prostaglandins and leukotrienes. The oil exhibited positive immunomodulatory effects, enhancing $\mathrm{T}$ cell and natural killer cell-mediated immune responses. In addition, the oil and its active ingredients show antimicrobial effects toward different bacteria $[7,10,11]$. Alchemilla plants are used in traditional medicine for the treatment of different diseases, including reducing the symptoms of sore throat, stopping bleeding, acting against gastrointestinal diseases and inflammatory processes, as well as for promoting wound healing due to its strong antimicrobial and anti-inflammatory effects. Therefore, the anti-oxidant, anti-inflammatory, and antibacterial properties of the three plants of HPC as separate plants. In particular, NS, alone and in combination (due to synergistic effects), seem to be the main mediators of the observed significant anti-hemorrhoid effects of HPC.

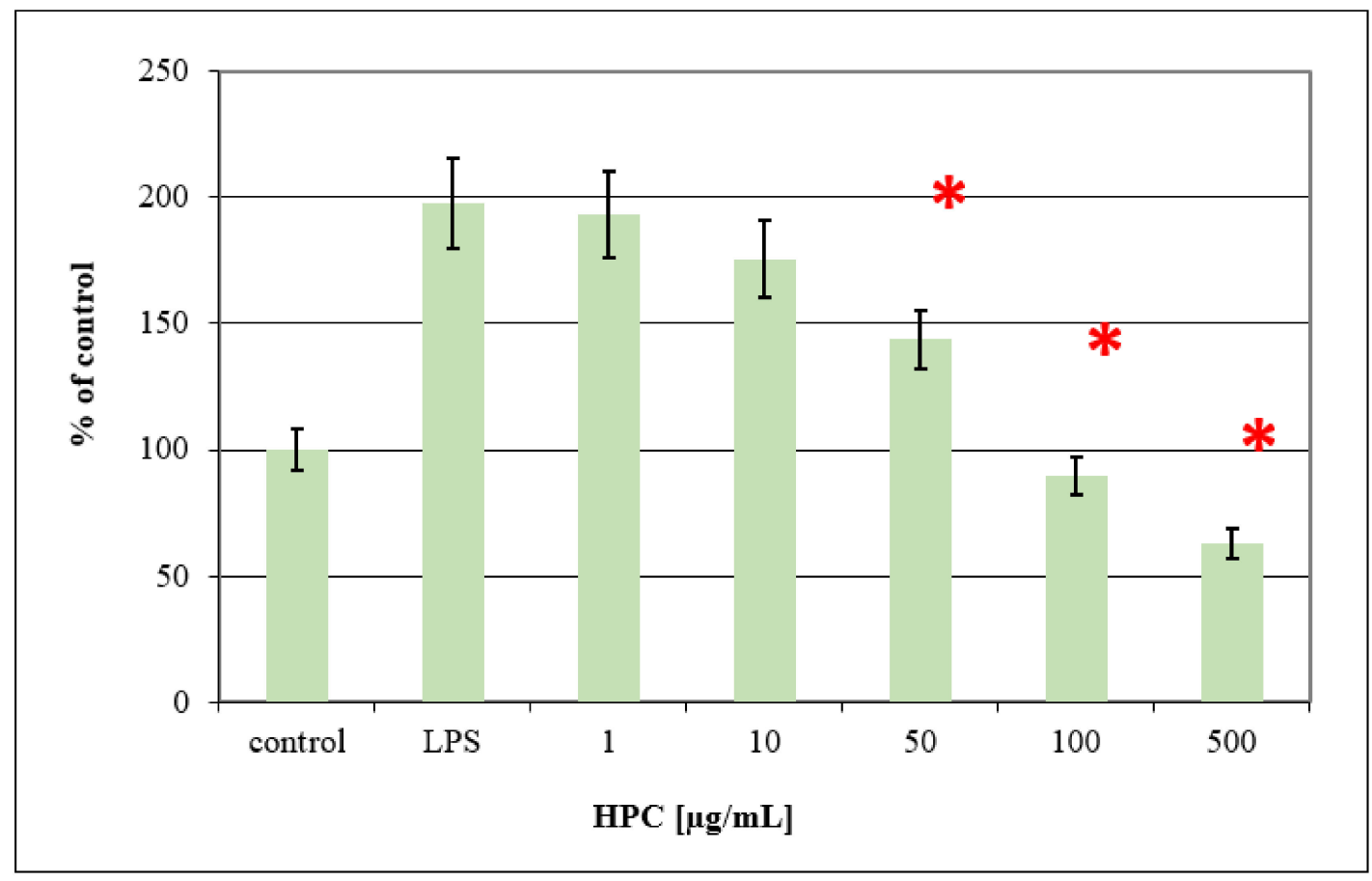

Figure 4. Dose-dependent inhibition of LPS mediated production of Nitric oxide (NO) in LPS-treated THP-1 cells by anti-hemorrhoidal polyherbal cream (HPC). For each concentration treatment, the level of NO release is represented as a percentage of the control set at $100 \%$. Values represent means \pm SD ( $p<0.05$ significant as compared to LPS alone) of three independent experiments carried out in triplicates.

\subsection{Vasoconstriction Effect of HPC on Intestinal Vein Rings}

The main symptoms of HD include enlargement and distal displacement of the normal anal clusters of veins, abnormal dilatation and distortion of the vascular channel, together with destructive changes in the connective tissue within the anal cushion. It seems that vascular hyperplasia and abnormal regulation of the vascular tone hyperplasia play an important role in HD development, and could be a potential target for topical medicinal plant-based treatment. In most cases, hemorrhoids are treated conservatively, using many methods such as lifestyle modification, fiber supplement, suppository-delivered antiinflammatory drugs, and administration of venotonic drugs $[1,4,5]$. Greco-Arab medicinal plant-based treatments are becoming popular in recent years [6,27]. Although there are reports on the vasoconstriction action of several medicinal plants, no information in the literature is available concerning vasoconstriction effects of $N S, C B$, or $A V$. Therefore, vaso- 
constriction was evaluated here to clarify if the anti-hemorrhoidal effects of these plants involves vasoconstriction mechanisms. The results shown in Figure 5 indicate a significant vasoconstriction effect of HPC in combination with phenylephrine. HPC increased the tension by $40 \%$. This effect can explain the ability of HPC to reduce vein swelling during inflammatory conditions.

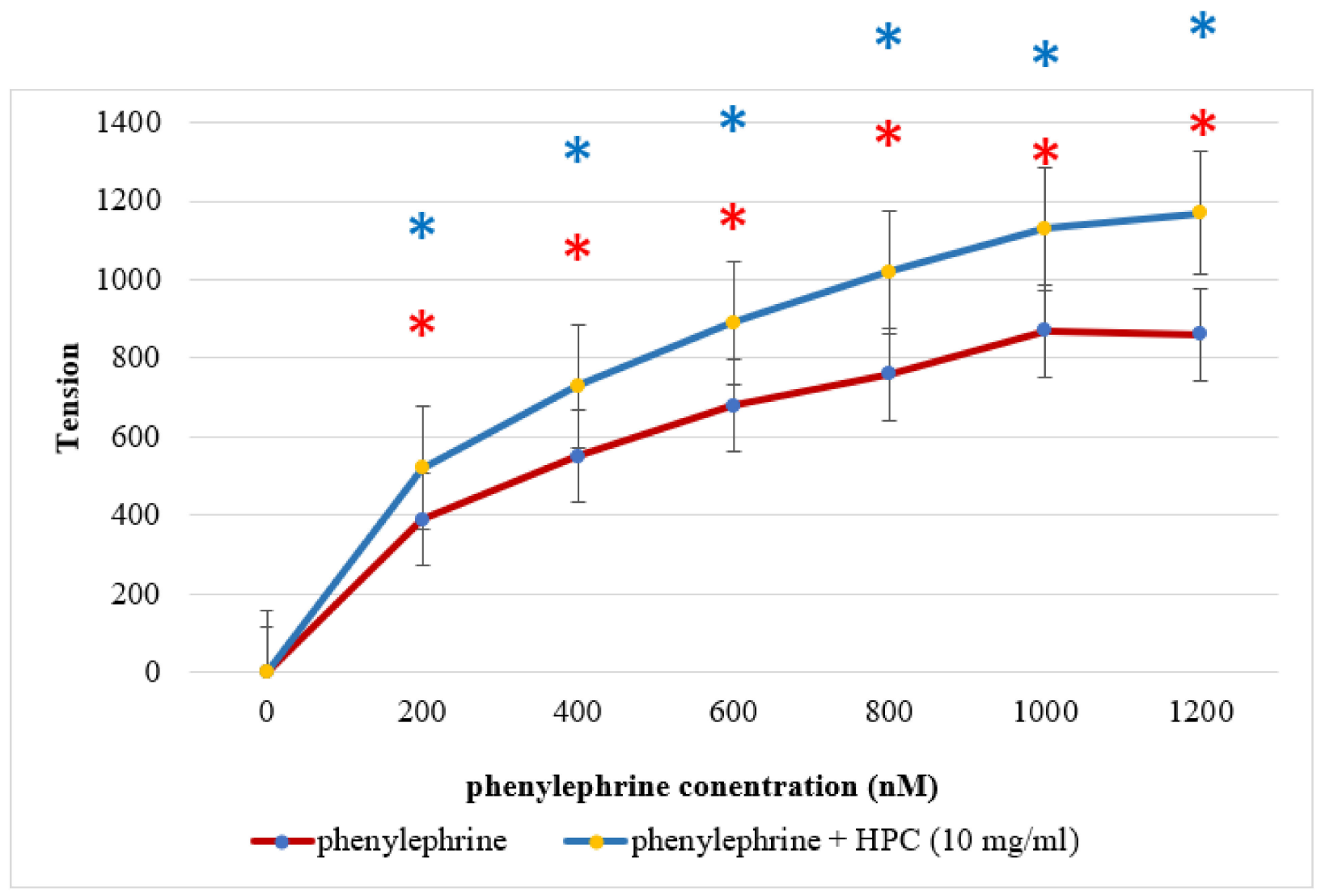

Figure 5. Vasocontraction effects of anti-hemorrhoidal polyherbal cream (HPC). Blood vessels were harvested from Sprague-Dawley male rats and treated with10 mg HPC/mL. Values represent means \pm SD of six independent experiments carried out in triplicates. ${ }^{*} p<0.01$ - significant as compared with control.

3.5. Open Label, Uncontrolled, Safety/Efficacy Study to Evaluate the Safety and Efficacy of HPC in the Treatment of Hemorrhoids

After obtaining the above-discussed positive in vitro results, we tested the safety and efficacy of HPC in the treatment of HD in an open-label, non-randomized, uncontrolled clinical study. This clinical study was carried out on 37 patients (17 females and 20 males, ages 19-59). The patients were asked to apply HPC twice daily for one week. Improvements in the severity degree of hemorrhoids (1-4), hemorrhage (0-3), pain (0-10), and itching (0-3) served us for evaluation of the HPC efficacy. The hemorrhoid severity degree for all the 37 patients was diagnosed as follows: 10 patients with degree 1, 18 with degree 2, and 9 with degree 3 . Figure 6 shows the obtained results. Almost all patients experienced a pronounced improvement in all four parameters tested.

\subsection{RDBPC to Determine the Anti-Hemorrhoidal Efficacy and Safety of HPC}

Although most of the currently used medicinal plants as well as their crude extracts in the management of HD have a history of traditional use, they lack sufficient evidence for approval as a new anti-hemorrhoidal drug. Therefore, the first advice is to complete efficacy and safety tests of these plants and then go through clinical trials to prove their efficacy $[2,5,6]$. Furthermore, polyherbal formulations of these herbs may be more useful 
by possible synergism that needs to be elucidated. Traditional Greco-Arab medicine as well as other and traditional medicines of different countries represent an invaluable source to discovery of effective drugs with lower prevalence of side effects compared to synthetic pharmaceuticals $[2,6,7]$. The mechanisms of action of these plants include antiinflammatory, anti-oxidant, anti-nociceptive, venotonic and venoprotective activities or even stool softening by absorption of water absorption. Different classes of phytochemicals, especially flavonoids, triterpenes, tannins, and terpenoids, may be responsible for the observed anti-hemorrhoidal activity of medicinal plants.

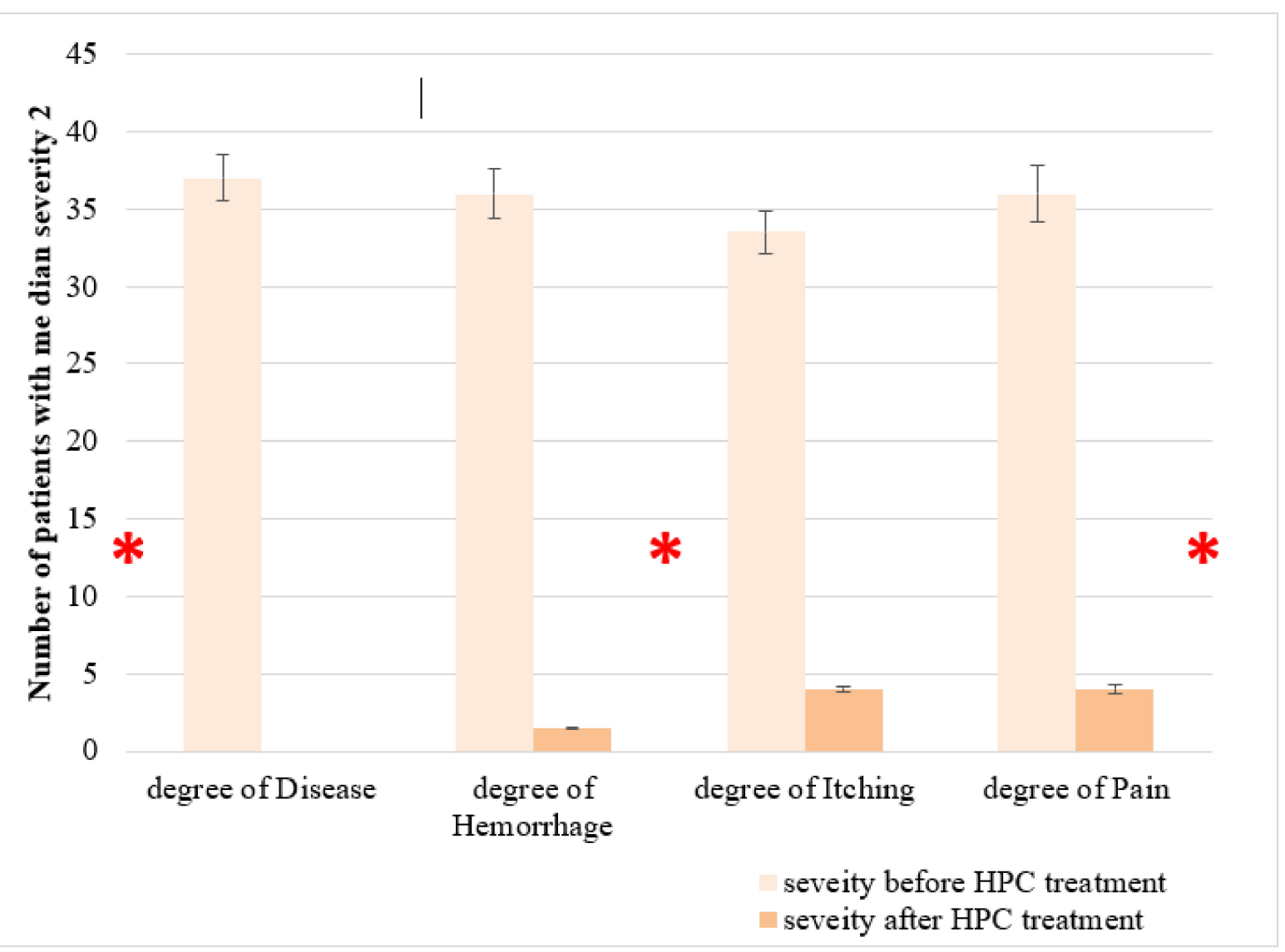

Figure 6. Effect of anti-hemorrhoidal polyherbal cream (HPC) on severity of hemorrhoids. The efficacy of HPC in the treatment of hemorrhoids was evaluated in an open label, non-randomized, uncontrolled clinical study. This clinical study was carried out on 37 patients (17 females and 20 males, ages 19-59). Values represent the number of patients with median severity $2 .{ }^{*} p<0.01$-significant as compared with control.

Topical treatments of hemorrhoids assist locally in calming inflammation and for stopping bleeding and swelling and are highly useful. The efficacy of a topical treatment with HPC, prepared from extracts from $N S, C B$, and $A V$, was evaluated in this study for the management of hemorrhoids. These plants have historical backgrounds in traditional medicine in topical treatment of hemorrhoids. In addition, their synergistic effects of HPC in improving the symptoms of hemorrhoids such as pain, bleeding, itching, hemorrhage severity, and quality of life were evaluated here.

Following up the results obtained by the open-label clinical study on 37 patients (17 females and 20 males, ages 19-59), we conducted a new wider RDBPC to determine the anti-hemorrhoidal efficacy and safety of HPC. The results showed that after 7 days of treatment with HPC, an improvement was observed in all patients during various time intervals in the treatment. There were improvements in the severity of the patients' major symptoms—severity of hemorrhoids (Degree 1-3) and hemorrhage severity (1-3) - 
compared to the placebo group (Figure 7). A significant effect of HPC was observed on Quality of life (QoL) of the patients (Degree 1-3), Pain (0-10 Scale), and Itching (0-3 Scale), compared to placebo (Figure 8 ). No side any effects were reported by any of the patients.

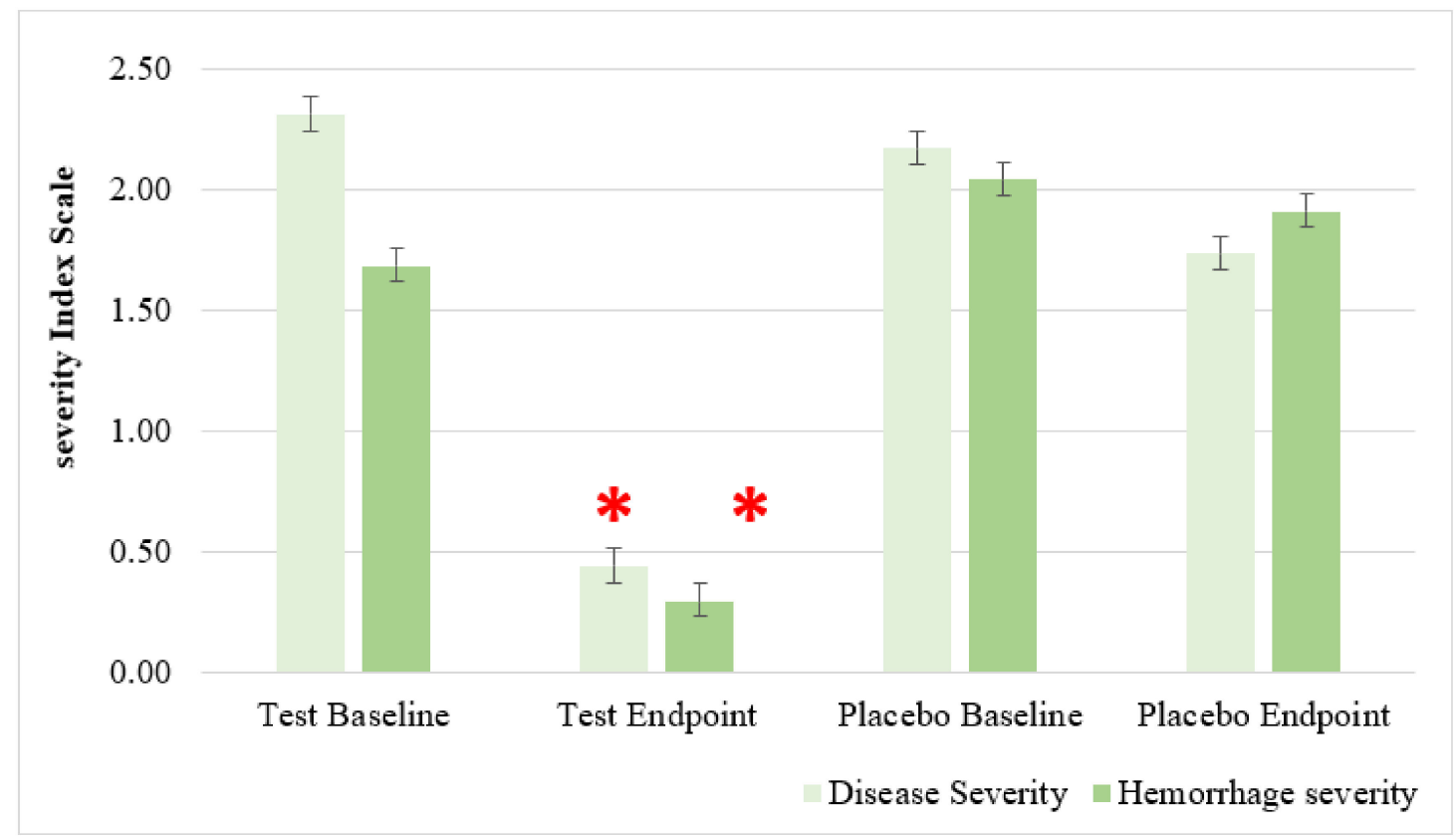

Figure 7. Effect of anti-hemorrhoidal polyherbal cream (HPC) on severity of hemorrhoids (Degree $1-3$ ) and hemorrhage severity (0-3), compared to placebo. Total participants $n=77$, HPC group $n=54$, placebo group. $n=23 .{ }^{*} p<0.01$ - significant as compared with control.

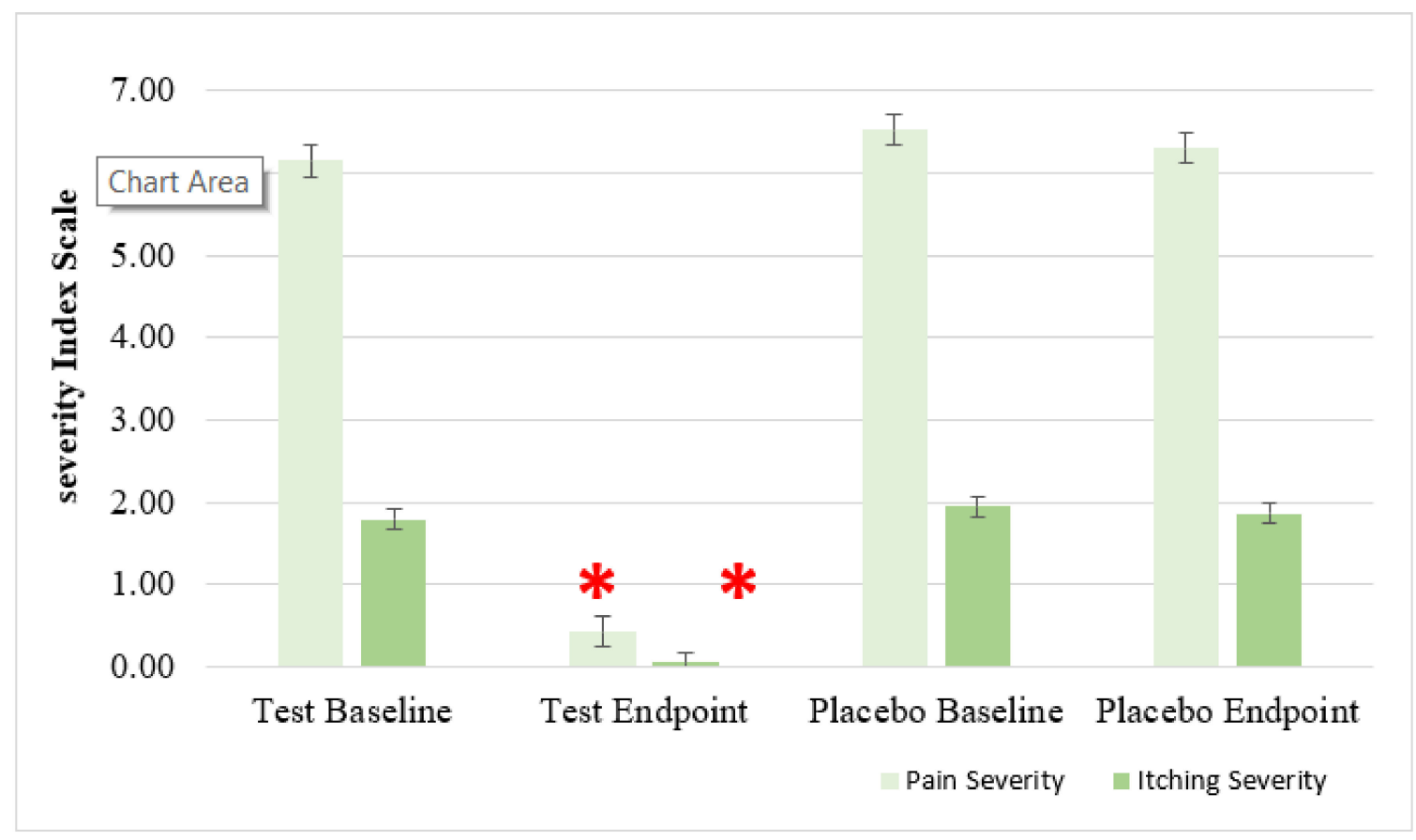

Figure 8. Effect of anti-hemorrhoidal polyherbal cream (HPC) on quality of life (QoL) of hemorrhoids (Degree 1-3), Pain (0-10 Scale) and Itching (0-3 Scale), compared to placebo. Total participants $n=77$, HPC group. $n=54$, placebo group. $n=23$. ${ }^{*} p<0.01$ - significant as compared with control.

Figure 9 shows the effect of HPC on hemorrhage severity, disease degrees 1-3, as compared to placebo. Improvement was especially evident for the symptom of hemor- 
rhage and no noticeable side effects were observed. Compared to placebo, treatment with HPC reduced the hemorrhage severity index to $0-1$ after 6 days. The mechanism may be related to the regulation of cytokines in the systemic and hemorrhoidal region, which increases the permeability of the blood vessels and improves the coagulation mechanism and lymphatic blood pressure [30,34]. As discussed above, there are many reports about the anti-inflammatory action of the three plants of HPC. Several immunomodulatory, antiinflammatory, and immunotherapeutic effects of NS and $A V$ have been published. These publications provide clear evidence that both crude extracts and its active compounds, in particular thymoquinone, exhibit significant anti-oxidant and anti-inflammatory effects through enhancing the oxidant scavenger system, decreasing the production levels of pro-inflammatory cytokines (e.g., IL- 6 and TNF- $\alpha$ ) and increasing the production of anti-inflammatory cytokines (e.g., IL-10). Furthermore, NS-derived oil and thymoquinone have also shown potent anti-inflammatory effects in several inflammation-based models including experimental encephalomyelitis, colitis, peritonitis, oedama, and arthritis through suppression of the pro-inflammatory mediators prostaglandins and leukotrienes. Most importantly, both the oil and its active ingredients expressed antimicrobial properties toward different microbes $[7,10,11] . A V$ is used in traditional medicine for different indications, including minimizing the symptoms of sore throat, stopping bleeding, acting against gastrointestinal diseases and inflammatory processes, as well as for promoting wound healing due to its strong antimicrobial and anti-inflammatory effects. Therefore, synergistic anti-oxidant, anti-inflammatory, and antibacterial properties of the three plants of HPC seem to be the main mediators of the observed significant hemorrhage effects of HPC.

A

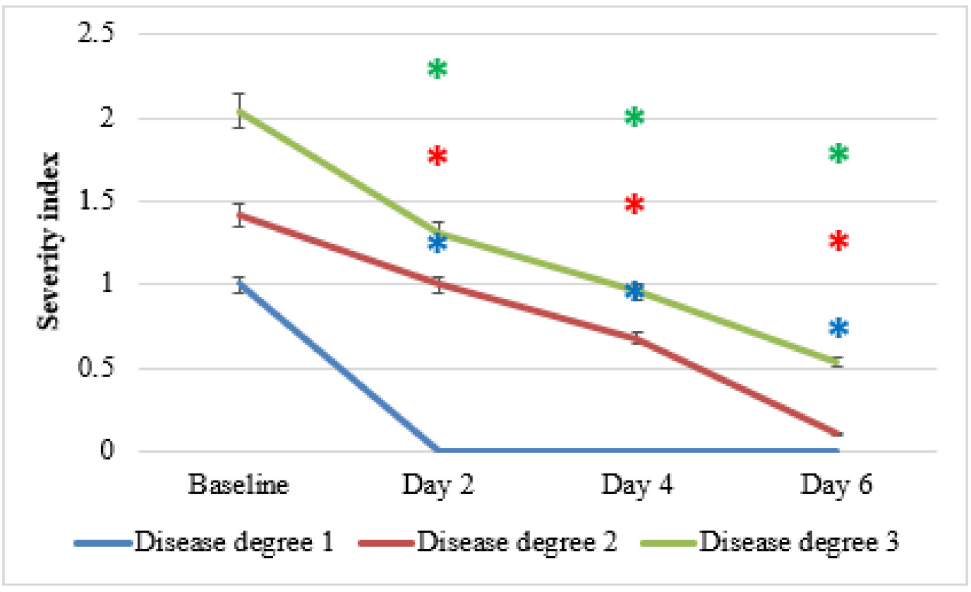

B

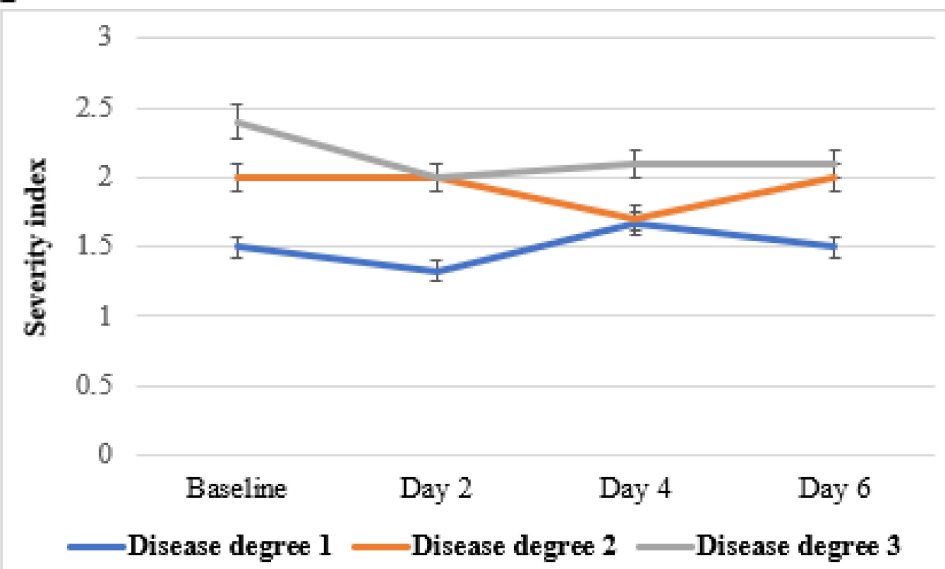

Figure 9. Effect of anti-hemorrhoidal polyherbal cream (HPC) (A) placebo (B) on hemorrhage severity. Disease Degree 1 (HPC, $n=9$; placebo, $n=7$ ), 2 (HPC, $n=7$; placebo, $n=7$ ), and 3 (HPC, $n=26$; placebo, $n=10)$. ${ }^{*} p<0.01-$ significant as compared with control. 
Figure 10 shows the effect of HPC on pain severity, degrees 1-3, as compared to placebo. Patients of all three levels of disease showed significant decreases in the severity of pain, reaching the highest effects (severity index of about 1 in the three severity degrees) on day 6 compared to placebo. Greco-Arab and Islamic herbal medicine use many medicinal plants in the management of pain. Among these plants, $A V$ and NS seeds are the sources of phytochemicals that have been researched for their therapeutic potential [35-39]. NS fixed oil, either topically or orally, is traditionally used for the management of pain in the back, joints, and musculoskeletal organs, as well as for rheumatoid arthritis. The observed anti-pain effects of HPC may be the results of a syncretic effect of all the plants of HPC.

A

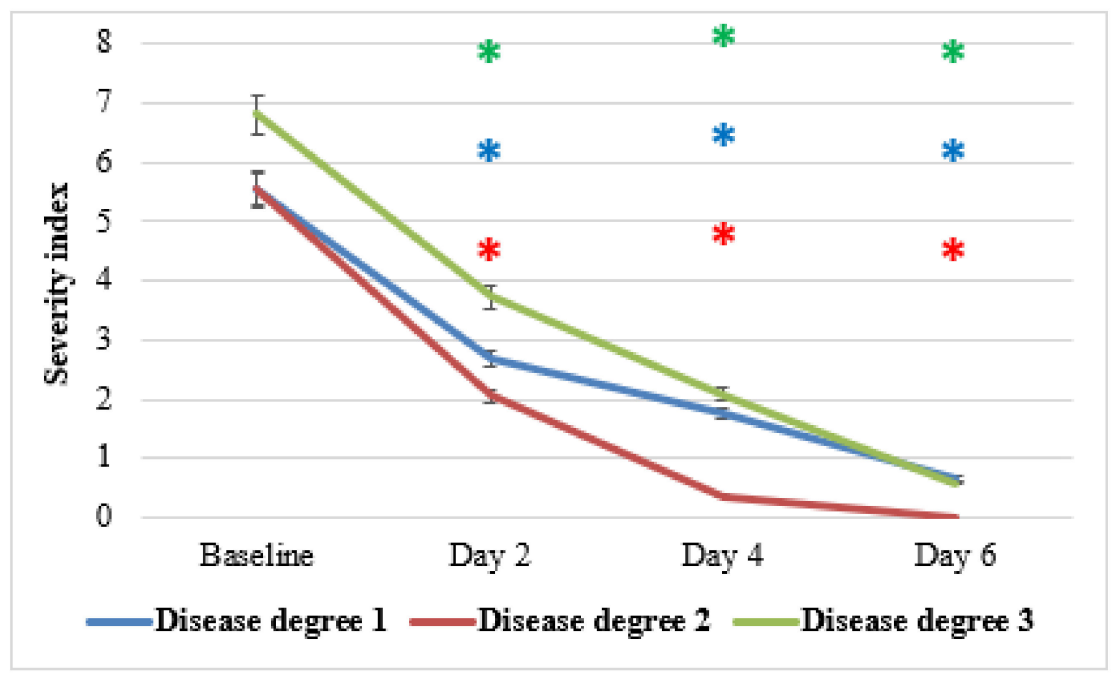

B

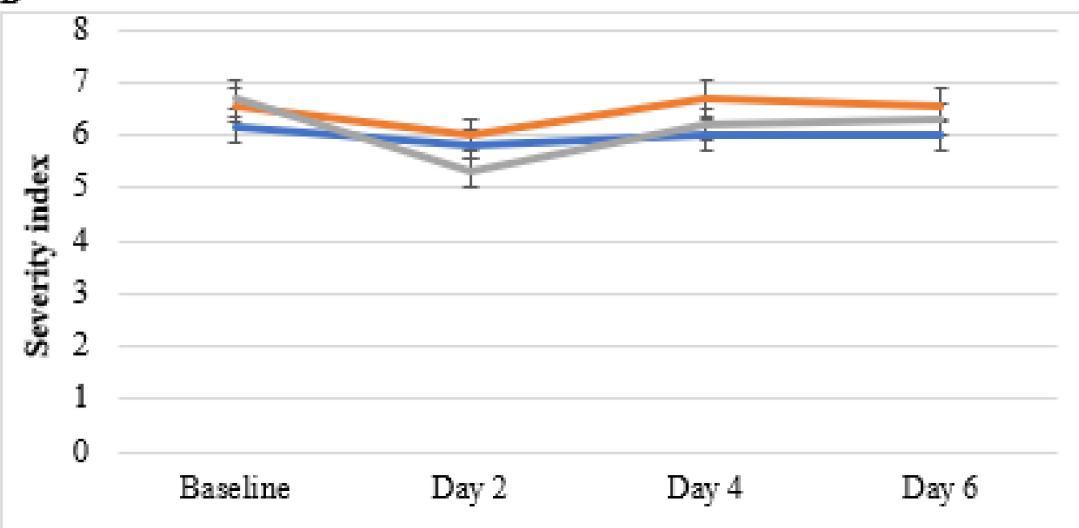

-Disease degree 1 -Disease degree $2-$ Disease degree 3

Figure 10. Effect of anti-hemorrhoidal polyherbal cream (HPC) on pain severity. Disease degree 1 (HPC, $n=9$; placebo, $n=7$ ), 2 (HPC, $n=19$; placebo, $n=7$ ), and 3 (HPC, $n=26$; placebo, $n=10$ ). * $p<0.01$-significant as compared with control.

Figure 11 shows the effect of HPC on pruritus ani (anal itching). Compared to placebo, HPC application brought about significant clinical responses almost immediately after the initiation of the treatment. Complete response up to resolution of the complaints was achieved towards the end of the treatment period. Importantly, this favorable clinical response was seen in all subjects regardless of their disease grade, although grade- 1 disease was more rapidly responsive in comparison to grades 2 or 3 . Subjects assigned for placebo did not report any improvement. NS fixed oil topically or orally is used traditionally for 
management all types of itching [36-40]. The observed anti-pain effects of HPC may be the result of NS alone or the result of a syncretic effect of all the plants of HPC.

A

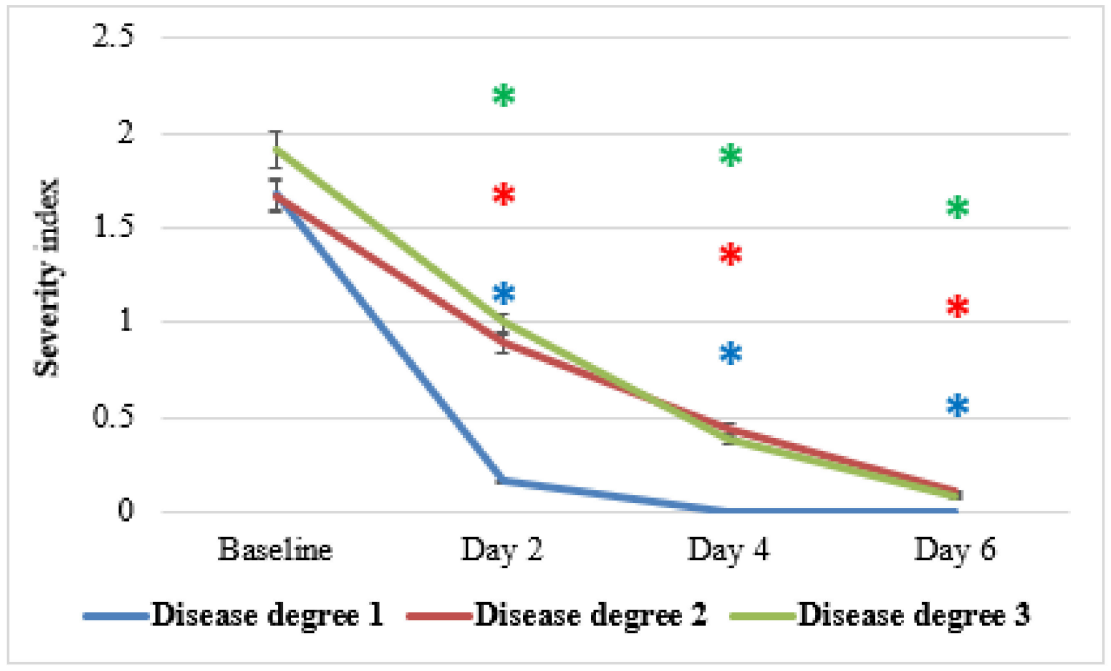

B

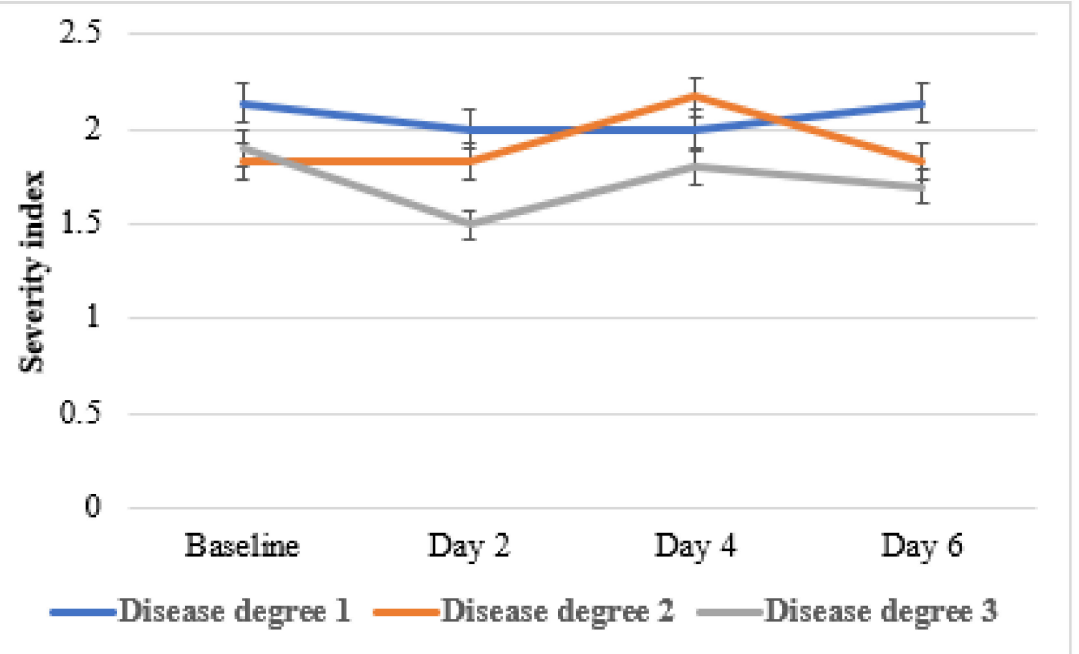

Figure 11. Effect of anti-hemorrhoidal polyherbal cream (HPC) on itching severity. Disease degree 1 (HPC, $n=19$; placebo, $n=7$ ), 2 (HPC, $n=9$; placebo, $n=6$ ), and 3 (HPC, $n=26$; placebo, $n=10$ ). ${ }^{*} p<0.01$-significant as compared with control.

\section{Conclusions}

HD is one of the most common gastrointestinal diseases. There are several conventional therapeutic options sometimes associated with complications. Therefore, researchers are looking for traditional medicines as a potential resource for the introduction of new natural drugs. The present in vitro, animal study, and randomized, double-blind, placebocontrolled trial aim to determine the efficacy and safety of HPC. Our in vitro study showed that HPC has significant antimicrobial, anti-inflammatory, and vasoconstriction effects. Following the promising results regarding the cytotoxicity, anti-inflammatory, anti- E. coli, and vasoconstrictive effects of HPC on intestinal vein rings, as well as an open label clinical study on 37 patients, we conducted a double-blind, placebo-controlled trial to determine the anti-hemorrhoidal efficacy and safety of HPC. This clinical trial included 77 patients suffering from symptomatic hemorrhoids in different grades. The patients were asked to apply HPC/placebo twice daily for 6 days. Each patient came to five visits as well as a follow-up visit: at baseline, at days $2,4,6$, and at the observation endpoint after one 
month. The obtained results show that patients treated with HPC had significant clinical improvement in all disease severity parameters compared to placebo.

A large number of over-the-counter remedies are available on the market because of the widespread attitude of patients to often choose to self-medicate with natural remedies instead of conventional medical treatments which are sometimes burdened by a problematic risk/benefit ratio that negatively affects their usefulness [31-33]. Therefore, it is important to search for effective and safe herbal-based alternatives. Given the rapid and comprehensive efficacy of HPC on all the different symptoms of HD, it can find a place in the treatment of this disease.

Author Contributions: O.S. (Omar Said), I.K. and S.F. performed the double blind, randomized, and controlled efficacy study. Investigation M.M.; B.S. (Bashar Saad), A.K., B.A., B.S. (Bashar Saad), O.S. (Omar Sadiq), B.S. (Besan Saied) and R.A. performed the in vitro studies. B.S. (Bashar Saad) and O.S. (Omar Said) were responsible for planning the study and are the main writers of the manuscript, in consultation with all authors. All authors have read and agreed to the published version of the manuscript.

Funding: This research received no external funding.

Institutional Review Board Statement: The study was conducted in accordance with the Declaration of Helsinki, and the protocol of the study was reviewed and approved by the ethics committee of the Rambam Hospital, Israel (ethics approval number/date: 0330-13-RMB/23072013). The study was conducted in accordance with the relevant guidelines and regulations of the ethics committee of the Rambam Hospital, Israel.

Informed Consent Statement: Informed consent was obtained from all subjects involved in the study.

Data Availability Statement: The data used to support the findings of this study are available from the corresponding author upon request.

Acknowledgments: The authors would like to acknowledge the Arab American University, Palestine (AAUP) and the Al-Qasemi Research Foundation for their financial support. The authors gratefully acknowledge the expert technical advice of Hisham Shaheen and Mohammad Abas.

Conflicts of Interest: The authors declare that they have no conflict of interest.

\section{References}

1. Thomson, W.H. The nature of haemorrhoids. Br. J. Surg. 1975, 62, 542-552. [CrossRef] [PubMed]

2. Rahimi, R.; Abdollahi, A. Evidence-based Review of Medicinal Plants Used for the Treatment of Hemorrhoids. Int. J. Pharmacol. 2013, 9, 1-11. [CrossRef]

3. Sneider, E.B.; Maykel, J.A. Diagnosis and management of symptomatic hemorrhoids. Surg. Clin. N. Am. 2010, 90, 17-32. [CrossRef] [PubMed]

4. Lohsiriwat, V. Hemorrhoids: From basic pathophysiology to clinical management. World J. Gastroenterol. 2012, 18, 2009-2017. [CrossRef]

5. Erbay, M.Ş.; Sarı, A. Plants used in traditional treatment against hemorrhoids in Turkey. Marmara Pharm. J. 2018, 22, 110-132. [CrossRef]

6. Saad, B.; Said, O. Arab medicinal plants: From traditional uses to scientific knowledge. In Greco-Arab and Islamic Herbal Medicine: Traditional System, Ethics, Safety, Efficacy and Regulatory Issues; Wiley-Blackwell John Wiley \& Sons Inc.: Hoboken, NJ, USA, 2011; pp. 149-228.

7. Saad, B.; Zaid, H.; Shanak, S.; Kadan, S. Anti-Diabetes and Anti-Obesity Medicinal Plants and Phytochemicals Safety, Efficacy, and Action Mechanisms; Springer: Cham, Switzerland, 2017.

8. Ben-Arye, E.; Cassileth, B.; Heusser, P.; Afifi, F.; Saad, B.; Senthamil, R.S. Complementary and Integrative Oncology in the Cross-Cultural Region of the Middle East and South Asia. Evid.-Based Complement. Altern. Med. 2012, 2012, 940961. [CrossRef]

9. Saad, B. Prevention and Treatment of Obesity-Related Cardiovascular Diseases by Diet and Medicinal Plants. In Herbal Medicine: Back to the Future; Vascular Health; Murad, F., Ur-Rahman, A., Bian, K., Bentham, Eds.; Bentham Science Publishers: Singapore, 2019; Volume 2, pp. 125-165.

10. Salem, M.L.; Hossain, M.S. Protective effect of black seed oil from Nigella sativa against murine cytomegalovirus infection. Int. J. Immunopharmacol. 2000, 22, 729-740. [CrossRef]

11. Yimer, E.M.; Tuem, K.B.; Karim, A.A.; Ur-Rehman, N.; Anwar, F.F. Nigella sativa L. (Black Cumin): A promising natural remedy for wide range of illnesses. Evid.-Based Complement. Altern. Med. 2019, 2019, 1528635. [CrossRef] 
12. Thabit, R.A.; Cheng, X.R.; Hajj, N.A.L.; Rahman, M.R.; Le, G.W. Antioxidant and Conyza bonariensis: A Review. Eur. Acad. Res. 2014, 2, 8454-8458.

13. Wu, H.; Graham, E.H. The biology of Australian weeds 49. Conyza bonariensis (L.). Cronquist Plant Prot. Q. 2007, $22,121-131$.

14. Said, O.; Khalil, K.; Fulder, S.; Azaizeh, H. Ethnopharmacological survey of medicinal herbs in Israel, the golan heights and the West bank region. J. Ethnopharmacol. 2002, 83, 251-265. [CrossRef]

15. Said, O.; Khamaysi, I.; Kmail, A.; Fulder, S.; Abo Farekh, B.; Amin, R.; Daraghmeh, J.; Saad, B. In vitro and a randomized, doubleblind, placebo-controlled trial to determine the efficacy and safety of nine anti-acne medicinal plants. Evid.-Based Complement. Altern. Med. 2020, 2020, 3231413. [CrossRef] [PubMed]

16. Ghedira, K.; Goetz, P.; Jeune, R.L. Alchemilla vulgaris . Phytothérapie 2012, 2012, 263-266. [CrossRef]

17. Boroja, T.; Mihailovi, V.; Katani, J.; Pan, S.; Nikles, S.; Imbimbo, P.; Monti, D.M.; Stanković, N.; Stanković, M.S.; Bauer, R. The biological activities of roots and aerial parts of Alchemilla vulgaris L. S. Afr. J. Bot. 2012, 2018, 175-184. [CrossRef]

18. Ding, A.H.; Nathan, C.F.; Stuehr, D.J. Release of reactive nitrogen intermediates and reactive oxygen intermediates from mouse peritoneal macrophages. J. Immunol. 1988, 141, 2407.

19. Said, O.; Fulder, S.; Khalil, K.; Azaizeh, H.; Kassis, E.; Saad, B. Maintaining a physiological blood glucose level with "Glucolevel”, a combination of four anti-diabetes plants used in traditional Arab herbal medicine. Evid.-Based Complement. Altern. Med. 2008, 5, 421-428. [CrossRef]

20. Said, O.; Saad, B.; Fulder, S.; Amin, R.; Kassis, E.; Khalil, K. Hypolipidemic activity of extracts from Eriobotrya japonica and Olea europaea, traditionally used in the Greco-Arab medicine in maintaining healthy fat levels in the blood. Open Complement. Med. J. $2009,1,1$.

21. Said, O.; Khalil, K.; Fulder, S.; Marie, Y.; Kassis, E.; Saad, B. A double blinded-randomized clinical study with "Weighlevel”, a combination of four medicinal plants used in traditional Greco-Arab and Islamic medicine. Open Complement. Med. J. 2009, 1, 100-115.

22. Saad, B.; Abou-Aatta, B.S.; Basha, W.; Hmade, A.; Kmail, A.; Khasib, S.; Said, O. Herbal-derived factors down regulate the production levels of nitric oxide and proinflammatory cytokine TNF-a in LPS-Activated THP-1 cells. Evid.-Based Complement. Altern. Med. 2008, 14, 586470.

23. Ali-Shtayeh, M.S.; Al-Assali, A.A.; Jamous, R.M. Antimicrobial activity of Palestinian medicinal plants against acne-inducing bacteria. Afr. J. Microbiol. Res. 2013, 7, 2560-2573.

24. Ljubuncic, P.; Said, O.; Ehrlich, Y.; Meddings, J.B.; Shaffer, E.A.; Bomzon, A. On the in vitro vasoactivity of bile acids. Br. J. Pharm. 2000, 131, 387-398. [CrossRef] [PubMed]

25. Takiuti, N.H. The effect of chronic nitric oxide inhibition on vascular reactivity and blood pressure in pregnant rats. Med. Investig. Lab. Braz. 1999, 117, 197-204. [CrossRef] [PubMed]

26. Timothy, M.; Kelly, L.; Chad, E. Hemorrhoids: Diagnosis and treatment options. Am. Fam. Physician 2018, 97, 172-179.

27. Saad, B.; Said, O. Arab medicinal plants: Herbal medicine. In Greco-Arab and Islamic Herbal Medicine: Traditional System, Ethics, Safety, Efficacy and Regulatory Issues; Wiley-Blackwell John Wiley \& Sons Inc.: Hoboken, NJ, USA, 2011; pp. 47-70.

28. Shah, N.Z.; Muhammad, N.; Azeem, S.; Khan, A.Z.; Samie, M.; Khan, H. Antimicrobial and phytotoxic properties of Conyza bonariensis. Pharm. Pharmacol. Res. 2013, 1, 8-11.

29. Said, O.; Saad, B.; Fulder, S.; Khalil, K.; Kassis, E. Weight Loss in Animals and Humans Treated with 'Weighlevel', a Combination of Four Medicinal Plants Used in Traditional Arabic and Islamic Medicine. Evid. Based Complement. Altern. Med. 2011, $2011,874538$. [CrossRef]

30. Haas, P.A.; Fox, T.A., Jr.; Haas, G.P. The pathogenesis of hemorrhoids. Dis. Colon Rectum 1984, 27, 442-450. [CrossRef]

31. Szlavy, L.; Repa, I.; Lengyel, I.; Lamboy, L. Calcium dobesilate (CLS 2210) protects the myocardium in early acute myocardial infarction: A preliminary randomized, double-blind, placebo-controlled study of its effects on biochemical markers. J. Cardiovasc. Pharmacol. 1990, 15, 89-95. [CrossRef]

32. Nasuti, C.; Fedeli, D.; Bordoni, L.; Piangerelli, M.; Servili, M.; Selvaggini, R.; Gabbianelli, R. Anti-Inflammatory, Anti-Arthritic and Anti-Nociceptive Activities of Nigella sativa Oil in a Rat Model of Arthritis. Antioxidants 2019, 8, 342. [CrossRef]

33. Mahboubi, M.; Kashani, L.M.T.; Mahboubi, M. Nigella sativa fixed oil as alternative treatment in management of pain in arthritis rheumatoid. Phytomedicine 2018, 46, 69-77. [CrossRef]

34. Choi, J.; Park, Y.G.; Yun, M.S.; Seol, J.W. Effect of herbal mixture composed of AVand Mimosa on wound healing process. Biomed. Pharmacother. 2018, 106, 326-332. [CrossRef]

35. Saad, B.; Ghareeb, B.; Kmail, A. Metabolic and epigenetics action mechanisms of antiobesity medicinal plants and phytochemicals. Evid.-Based Complement. Altern. Med. 2021, 2021, 9995903. [CrossRef] [PubMed]

36. Saad, B.; Azaizeh, H.; Said, O. Arab herbal medicines. In Botanical Medicine in Clinical Practice; Watson, R.R., Preedy, V.R., Eds.; CABI: Wallingford, UK, 2008.

37. Gholamnezhad, Z.; Havakhah, S.; Boskabady, M.H. Preclinical and clinical effects of Nigella sativa and its constituent, thymoquinone: A review. J. Ethnopharmacol. 2016, 190, 372-386. [CrossRef] [PubMed]

38. Saad, B.; Azaizeh, H.; Said, O. Tradition and perspectives of Arab herbal medicine: A Review Evid. -Based Complement. Altern. Med. 2005, 2, 475-479. [CrossRef] [PubMed] 
39. Azaizeh, H.; Saad, B.; Khaleel, K.; Said, O. The state of the art of traditional Arab herbal medicine in the eastern region of the Mediterranean: A review Evid. -Based Complement. Altern. Med. 2006, 3, 229-235. [CrossRef] [PubMed]

40. Saad, B.; Azaizeh, H.; Hijleh, G.A.; Said, O. Safety of traditional Arab herbal medicine. Evid.-Based Complement. Altern. Med. 2006, 3, 433-439. [CrossRef] 